Anuario Latinoamericano Ciencias Políticas y Relaciones Internacionales vol. 11, 2021

pp. $147-164$

\section{La vigencia del pensamiento de Juan Bautista Alberdi en el contexto latinoamericano: el rol del empresario ${ }^{1}$}

\author{
The Validity of the Thought of Juan Bautista Alberdi in the \\ Latin American Context. The Role of the Businessman²
}

\author{
Miguel Francisco Gutiérrez ${ }^{*}$ \\ FACULTAD DE CIENCIAS ECONÓMICAS \\ UNIVERSIDAD DE BUENOS AIRES, ARGENTINA \\ Sumadesarrollo2030@gmail.com \\ https://orcid.org/0000-0003-4702-7393
}

\title{
RESUMEN
}

El objetivo de este artículo es presentar, en el actual contexto latinoamericano, la vigencia del pensamiento de Juan Bautista Alberdi (JBA) respecto de las condiciones necesarias para superar el estado de pobreza, así como revelar las condiciones institucionales y el rol de los emprendedores sobre las dinámicas de generación de valor. La metodología utilizada se basa en el análisis documental de la obra y de fuentes secundarias relevantes al estudio de su pensamiento. Presentar el pensamiento de Alberdi da cuenta de la relevancia de sus diagnósticos sobre la pobreza y las limitaciones de oportunidades del conjunto de países latinoamericanos.

PALABRAS CLAVE: Juan Bautista Alberdi, emprendedor, valor, pobreza, crisis, instituciones.

\section{ABSTRACT}

The objective of this article is to present, in the current Latin American context, the validity of the thought of Juan Bautista Alberdi (JBA) regarding the necessary conditions to overcome the state of poverty as well as to reveal the institutional conditions and the role of entrepreneurs over the dynamics of value generation. The methodology used is based on the documentary analysis of his work and secondary

* Doctorando en Ciencias Económicas de la Universidad de Buenos Aires. Profesor Adjunto regular e investigador con dedicación exclusiva de la Facultad de Ciencias Económicas de la Universidad de Buenos Aires.

1 El presente documento revela parte de las conclusiones de investigación enmarcadas en la realización doctoral en Ciencias Económicas en la Universidad de Buenos Aires por parte del autor.

2 This document reveals part of the research conclusions of the author's doctoral studies in Economic Sciences at the University of Buenos Aires. 
sources relevant to the study of his thought. The presentation of Alberdi's thought shows the relevance of his diagnoses on poverty and the limitations of opportunities in all Latin American countries.

KEYWORDS: Juan Bautista Alberdi, entrepreneur, value, poverty, crisis, institutions.

\section{Introducción}

El objetivo de este articulo es presentar el análisis de la relación entre las condiciones institucionales, el rol de los emprendedores y las crisis sobre las dinámicas de generación de valor en la Argentina del siglo XIX en el pensamiento de Juan Bautista Alberdi (JBA). Se presentan aquí parcialmente los resultados de la investigación doctoral respecto del pensamiento de Alberdi para dar cuenta de la relevancia de sus diagnósticos sobre la pobreza y las limitaciones de oportunidades del conjunto de países latinoamericanos.

La investigación se planteó contrastar el aporte del pensamiento de Juan Bautista Alberdi a las ciencias económicas identificando los condicionantes del crecimiento basado en las características institucionales, el rol de los empresarios/emprendedores y la estructura productiva de la Argentina del siglo XIX. Su pensamiento representa la base del estudio de las condiciones institucionales necesarias para lograr incentivos favorables a la organización del trabajo productivo como articulador social.

El estudio pormenorizado del pensamiento de Alberdi desde las ciencias económicas es una tarea pendiente. ${ }^{3}$ Por lo tanto, llevar a cabo el estudio del sistema institucional que Alberdi considera necesario para superar la condición de pobreza que caracteriza a la economía argentina será un aporte novedoso para el estudio del pensamiento de las ciencias económicas. El análisis de las crisis económicas como expresión de las condiciones de pobreza depende del orden institucional y del papel de la iniciativa privada en la organización social (North, 2014).

El pensamiento de Alberdi está influenciado por su formación en la literatura económica clásica (Adam Smith, David Ricardo y Jean-Baptiste Say) y por la filosofía política liberal romántica (Henri de Saint-Simon, Charles Fourier, Friedrich Karl von Savigny y Pierre Leroux, principalmente) (Tarcus, 2016, p. 119). Estas dos influencias caracterizaron sus propuestas en temas económicoinstitucionales de una forma particular. Sus aportes se inscriben en la matriz de

3 La contribución de Juan Bautista Alberdi a la teoría de las crisis es un capítulo indebidamente omitido en la historia del pensamiento económico. La causa de tal omisión reside en que Alberdi no hizo nunca una exposición compacta y coherente de sus ideas sobre las crisis. Los elementos esenciales de lo que (sin exageración) puede llamarse la teoría alberdiana de las crisis se hallan dispersos en forma desordenada a lo largo de sus reflexiones acerca de este asunto. Se requiere un trabajo de análisis para identificar esos elementos y para amalgamarlos en una estructura teórica apropiada. (Olivera, 1977, p. 76) 
la Modernidad, entendida como una época caracterizada por la racionalidad científica como medio de transformación social, por un cambio epistémico que transita de la religión a la ciencia, de la fe a la razón, desde el conocimiento revelado al conocimiento empírico y objetivo y al dominio de la naturaleza. Este abordaje moderno y liberal será el mismo que impulse el estudio de la eficiencia productiva como espacio científico de las ciencias económicas.

Este movimiento moderno se concibe liberal y universal como proceso; no obstante, la particularidad en Alberdi es que está presente la influencia romántica (Tarcus, 2016). Así, su característica diferencial como pensador de las ciencias económicas alimenta un imaginario político secularizado y teleológico que inventa la historia como progreso y que tiene como utopía final una república soberana, idealizada y feliz (Halperín Donghi, 2007).

La pregunta de investigación en la que se basa el presente trabajo se refiere a identificar ¿Cuál es la relación entre las “crisis de empobrecimiento", el rol de los "empresarios/emprendedores" y las "instituciones" en el pensamiento de Juan Bautista Alberdi?

\section{Metodología utilizada}

La metodología cualitativa fue utilizada en el presente artículo: técnicas de análisis documental, revisión bibliográfica y entrevistas abiertas en profundidad (análisis del discurso) a especialistas en la obra de Alberdi, historiadores, licenciados en Administración y economistas.

La historia de las ciencias económicas presenta algunas características particulares que la describen y diferencian tanto de la ciencia económica como de la historia. Entre sus principales especificidades se encuentra la de deber remitirse a un número mayor de variables de análisis de los procesos bajo estudio. En la ciencia económica, el estudio se encuentra enfocado en la prospectiva de los resultados, mientras que en la historia los objetivos están en la descripción de los hechos. En la historia económica, el foco está en la descripción de los procesos con un número mayor de datos, variables y procesos.

Este es el foco de la presente investigación: el pensamiento de JBA en materia económico-administrativa y en cuanto al rol de los empresarios/emprendedores en los procesos de generación de valor y distribución del ingreso. Su estudio nos remitirá a indagar en las influencias, las lecturas y finalmente las formulaciones que haya realizado Alberdi a lo largo de su producción intelectual.

\section{Resultados alcanzados}

A lo largo del presente artículo hemos recuperado el análisis del pensamiento de Juan Bautista Alberdi respecto de las condiciones necesarias para consolidar la independencia argentina. El empresario/emprendedor será el actor representati-
La vigencia del pensamiento de Juan Bautista Alberdi en el contexto latinoamericano: el rol del empresario

Miguel Francisco Gutiérrez 
vo de este proceso mediante las decisiones de ahorro e inversión. Los emprendedores/empresarios realizan su progreso material, potenciado por y dependiente de las condiciones institucionales de paz, seguridad, estabilidad y propiedad. Las instituciones representan el resultado de este proceso y se constituyen como los instrumentos de cambio (medios) que JBA articuló en su teoría del valor.

JBA planteó una reforma de las instituciones heredadas de la Colonia, que basaban su esquema de distribución de la renta en estructuras económicas de alta concentración, donde los monopolios eran una de las estrategias de control y de apropiación del excedente (el puerto único en Buenos Aires). También centró sus propuestas en la necesidad de lograr un régimen institucional estable que redujera el nivel de conflicto y garantizara seguridad y previsión, para establecer procesos de largo plazo de inversión y trabajo que produjeran un crecimiento económico estable y continuo.

La escasez de recursos, la pobre dinámica de acumulación y crecimiento y el alto nivel de violencia (guerra civil) imperante en la sociedad llevaron a JBA a concentrar sus críticas sobre el uso de recursos públicos en gastos militares, el endeudamiento, la pérdida del valor de la moneda y la falta de un federalismo representativo efectivo.

Los aportes analizados desde la economía institucional nos invitan a reflexionar sobre el pensamiento de Alberdi respecto de la necesidad de establecer mecanismos de regulación que impulsen instituciones inclusivas (Acemoglu \& Robinson, 2012). Mediante estrategias de desarrollo en que los sectores dinámicos de acumulación sean generadores de conocimiento y permitan la diversificación productiva necesaria, se logrará un nuevo sistema de valores para alcanzar la independencia.

El aporte de este artículo cuenta con un límite temporal, dado que analiza el pensamiento de un intelectual que integró y correlacionó conocimientos de diversos campos para indagar en las condiciones necesarias, desde la regulación de la vida social y económica, para construir un país próspero y una sociedad libre. El momento histórico, que coincide con el nacimiento de la ciencia de la administración (comienzos del siglo XX), representa nuevos desafíos institucionales y asociativos de un mercado en crecimiento y en el uso especializado de los factores de producción.

\section{Las instituciones y el rol del "empresario/emprendedor"}

Los incentivos son estímulos que despiertan nuestra motivación y, consecuentemente, nos mueven a alcanzar nuestros objetivos. Alberdi adhiere a una aproximación a este fenómeno desde un enfoque individual: "No es por la benevolencia del carnicero, del cervecero y del panadero que podemos contar con nuestra cena, sino por su propio interés" (Smith, 2011, p. 25).

El análisis de la relación entre incentivos e instituciones republicanas ha llevado al estudio de comportamientos regulatorios basados en la maximiza- 
ción política. James Buchanan, premio nobel de Economía en 1989, analiza, mediante la teoría de la elección pública, como los dirigentes intentan maximizar la posibilidad de ser reelegidos.

Podría argumentarse que los ciudadanos han llegado a esperar pan y circo de sus políticos. Si sus políticos no ofrecen tales cosas, elegirán a otros políticos en su lugar. En vista de estas perspectivas, hay pocos políticos dispuestos a negarse a ofrecer pan y circo. Después de todo, ¿no es más agradable cumplir que rechazar los deseos de su electorado? (Buchanan et al., 2000)

Alberdi condiciona el comportamiento del actor individual al ordenamiento institucional vigente. En este sentido, la herencia colonial de instituciones que no centraban los incentivos en el uso intensivo de los factores de producción en la búsqueda de incrementar la generación de valor y el producto $(\mathrm{PBI})$ representa una limitación al progreso. La visión de JBA del emprendedor/empresario se manifiesta en el siguiente fragmento.

Con nociones menos españolas y más exactas sobre la naturaleza verdadera de la riqueza, se daría a la tierra en Sud-América otro valor. No menos que su valor real, sino su verdadero valor. La América antes española no perdería en ello, porque realmente ocupa la tierra más capaz de ser rica, con otro orden de cosas que el actual, en que no es sino mero instrumento de riqueza, pero instrumento sin instrumentista.

Ese instrumentista, es decir, el trabajador inteligente, activo, enérgico, económico y juicioso, bien entendido; en una palabra, el trabajador de la Europa actual, inmigrado y establecido en el suelo americano. (Alberdi, 1895b, p. 72)

Es relevante la comparación del enfoque de Alberdi respecto de las condiciones necesarias para el incremento de la riqueza en el territorio, en relación con las motivaciones o incentivos que determinaron las instituciones coloniales. La extracción de valor de los territorios y la limitación de la generación de capacidades locales representó la base del modelo de extracción que heredaron nuestras instituciones de la colonia (Gutiérrez, 2019) . En este sentido, para Alberdi, los perfiles de los actores de la conquista americana expresan, al igual que para Acemoğlu y Robinson (2014), la búsqueda de rentas y la formación de instituciones políticas y económicas que limitan el desarrollo de capacidades e independencia de los territorios.

La riqueza fácil, ya formada, descubierta, que se obtiene sin la doble pena del trabajo y el ahorro, es la riqueza apetecida por el aventurero, por el noble, por el soldado, por el soberano...

La riqueza, así nacida, no era hija de las virtudes del trabajo y el ahorro. Como la riqueza griega y romana primitiva, era hija de la fuerza y de la
La vigencia del pensamiento de Juan Bautista Alberdi en el contexto latinoamericano: el rol del empresario

Miguel Francisco Gutiérrez 
injusticia: un robo hecho al suelo por un trabajo robado al hombre. (Alberdi, 1895b, p. 107)

Este argumento se analiza en el trabajo de Graeber (2012) en relación con estudio de la evolución de las instituciones. En los períodos históricos de inestabilidad institucional (guerra) se incrementa el uso del dinero-mercancía con relación a los períodos de paz. En tiempos de estabilidad y previsibilidad el dinero adquiere una conformación de convención (de cooperación en el tiempo) y los intercambios se fortalecen en relaciones de largo plazo ancladas en el trabajo y la confianza.

El inmigrado europeo pudo arrancar a la tierra sus metales preciosos por el trabajo del esclavo, pero no fue libre de ejercer su propio trabajo, para hacerle producir el cáñamo, la uva, la morera, el algodón, el trigo, el azúcar, el indigo; ni trabajar estas materias primas, para producir vinos, tejidos, muebles, comestibles ni otro objeto esencial a la vida social.

Prohibido el trabajo, no había producción ni riqueza. Faltando la producción, no había comercio. Es lo que necesitaba España para asegurar sus colonias. En su idea, el comercio era un peligro en emancipación, tanto de América consigo misma como con el extranjero.

Desde que la producción industrial estaba prohibida por la ley, el comercio no tenía razón de ser, ni podía existir.

El poblamiento de tales países debía ser lento. Como España misma no abundaba de población, la emigración para América estaba restringida.

La España, pueblo militar y religioso, colonizando el nuevo mundo, no cedió a mira alguna económica, ni comercial, ni industrial. (Alberdi, 1895b, p. 108)

Esta caracterización expone el tipo de instituciones heredadas de la Colonia y los esquemas de incentivos presentes en el territorio de la independencia. Por eso señala Alberdi la necesidad de transformación de las condiciones institucionales para gobernar las condiciones económicas. Para avanzar en la transformación de las instituciones, su aporte más conocido es evidentemente su propuesta de Constitución. Es mediante el avance de las transformaciones regulatorias que se modificarán los incentivos, las preferencias adaptativas de los agentes $y$, en último lugar, sus comportamientos.

Se trata únicamente de hacer de la Constitución una verdad de hecho, en los cuatro o seis artículos que forman toda su originalidad de Constitución Argentina, es decir, de la ley que responde a las cuatro necesidades que ese país tiene, y son: un gobierno estable, población, capital, riqueza, seguridad.

Todo lo demás vendrá a su vez, como derivación lógica de esas causas.

Estabilidad significa paz.

Seguridad significa libertad. 
Población significa trabajo.

Trabajo y capital significan riqueza, bienestar, poder o independencia, progreso y civilización. (Alberdi, 1895b, p. 434)

Estos hechos son para Alberdi el punto de mira hacia la construcción de un futuro de libertad, en que las capacidades se sustenten en el hacer, en el trabajo humano orientado al mercado. Este futuro imaginado contrasta con los tres siglos del pasado colonial, en que el despotismo era la base de la organización institucional, en que el mercado no existía en libertad; en suma, un orden institucional organizado para eliminar la libertad y la iniciativa privada de todo tipo (Acemoğlu y Robinson, 2012). Estudiar, rezar y legislar eran las acciones más honorables del período anterior, carentes de valor de progreso y de promoción de las riquezas de los bienes necesarios para un país civilizado.

En este contexto, el desarrollo de la institución "mercado" depende del fortalecimiento del Estado. Sin él, no es posible concebir los mercados competitivos modernos a los que Alberdi hace referencia.

De hecho, el Estado y sus poderes coercitivos fueron los que tuvieron que ver con la creación de lo que ahora conocemos como "el mercado", ya que se basa en instituciones como la propiedad privada, las monedas nacionales, los contratos legales, los mercados de crédito. Todo tuvo que ser creado y mantenido por políticas gubernamentales. El mercado fue una creación del gobierno y asi ha permanecido siempre. Si reflexionamos sobre los presupuestos de los economistas respecto del comportamiento humano, veremos que tiene sentido que fuera asi: después de todo, el principio de maximización da por sentado que la gente intentará extraer todo lo que pueda de aquellos con quienes está tratando, sin considerar en absoluto los intereses de los otros; pero al mismo tiempo supone que jamás, bajo ninguna circunstancia, recurrirá a ninguno de los modos más obvios de extraer riqueza de aquellos cuyo destino le resulta indiferente, tal como tomar la riqueza por la fuerza. El "comportamiento de mercado" sería imposible sin policía. (Graeber, 2018, p. 49)

Son las instituciones las que viabilizan las posibilidades de funcionamiento de los mercados como espacios de producción y realización del valor. Este sistema institucional de incentivos inclusivo promueve las posibilidades de desarrollar capacidades individuales y los incentivos necesarios para fomentar procesos de ahorro e inversión (procesos de generación de capital). Esto depende de las instituciones, en sentido amplio, como esquema de regulación social y económico.

La necesidad de crear instituciones tiene una clara conexión con el papel de los códigos de conducta, ya que las instituciones basadas en mecanismos interpersonales y entendimientos compartidos funcionan a partir de pautas de conducta comunes, de la confianza mutua y de la confianza en la ética
La vigencia del pensamiento de Juan Bautista Alberdi en el contexto latinoamericano: el rol del empresario

Miguel Francisco Gutiérrez 
del otro. La utilización de reglas de conducta normalmente está implícita más que explícita; de hecho, tan implícita que su importancia puede pasarse por alto con facilidad en las situaciones en las que esa confianza no plantea problemas. Pero siempre que plantea problemas, puede ser desastroso pasar por alto la necesidad de que exista confianza. (Sen, 2000, p. 318)

No obstante lo anterior, es relevante señalar el rol del Estado en la nueva configuración del mercado y de las relaciones mercantiles y sociales. Estas nuevas funciones y regulaciones son compartidas por Alberdi como condiciones necesarias para establecer incentivos correctos que promuevan la toma de decisiones relativas al ahorro y la inversión. Este cambio institucional del rol del Estado se consolida con la revolución liberal de fines del siglo XVIII, expresada en la Revolución francesa.

Pues es un error elemental (y no compartido por los lógicos protagonistas del capitalismo, los "filósofos radicales" benthamitas) el de creer que el liberalismo era hostil a la burocracia. Era hostil solamente a la burocracia ineficaz, a la intromisión pública en cuestiones que debían dejarse a la iniciativa privada, y a las contribuciones excesivas. El vulgar tópico liberal de un Estado reducido a las atrofiadas funciones de un vigilante nocturno oscurece el hecho de que el Estado libre de sus funciones ineficaces e inadecuadas era un Estado mucho más poderoso y ambicioso que antes. (Hobsbawm, 2015, p. 185)

Esta nueva organización institucional representa una necesaria disponibilidad de recursos y una modernización del Estado y de sus sistemas de control, recaudación y servicios. El Estado liberal comprende nuevas funciones relativas a garantizar las condiciones para el desarrollo del sistema de intercambios por precios: promueve funciones relativas a la estabilidad de un sistema monetario y de recaudación de impuestos que valide sus funciones y su soberanía (en presencia y prestación de funciones).

De esta forma, el Estado, en el conjunto institucional del siglo XIX, incrementa sus capacidades, funciones y complejidad. Esta reflexión también está presente en Alberdi respecto de los desafíos necesarios para superar el estado de pobreza natural del territorio argentino. Las instituciones deben superar sus funciones extractivas y proveer garantías de seguridad, propiedad, estabilidad y paz de largo plazo que promuevan el marco regulatorio necesario para el desarrollo del mercado.

\section{La riqueza depende del emprendedor}

El estudio del trabajo, el ahorro y la inversión como características morales que describen a las sociedades civilizadas en el pensamiento de Alberdi corresponde al análisis del valor y la riqueza, relevante para esta investigación. 
Analizaremos a continuación las características de estas categorías en el pensamiento de Alberdi y la articulación entre los diferentes procesos que describen la generación de valor y el progreso social en su visión. Así pues, en el análisis del emprendedor/empresario como agente de transformación social, nos centraremos en las condiciones necesarias y suficientes para la generación de valor, para la generación de ciclos de riqueza y para la transformación de los incentivos

El trabajo sud-americano carece todavía de las condiciones que hacen del trabajo europeo una verdadera fuente de riqueza. El ahorro es desconocido.

Dada esta situación en el suelo más capaz de ser un instrumento poderoso de producción, en manos de un trabajo inteligente y capaz, todo el problema de su transformación económica se reduce a buscar el medio de poner ese suelo en manos del trabajo y del trabajador de la Europa más adelantada, haciéndolo inmigrar en grande escala en el suelo que le reclama, sin perjuicio del mantenimiento integro de su nacionalismo y de su independencia. (Alberdi, 1895a, p. 715)

Alberdi analiza la teoría smithiana referida a la formación de capital como proceso de generación de riqueza. En Smith, los factores de los que depende la formación de capital - y en consecuencia el crecimiento- se encuentran en la extensión del mercado y en la proporción de la fuerza de trabajo productiva en relación con la fuerza de trabajo improductiva (2011, p. 52). La riqueza de una nación depende en última instancia de la acumulación de capital, y es esta visión la que adopta Alberdi.

Los factores estructurales del crecimiento económico están para Alberdi en la proporción de trabajadores productivos (no en la importación de capital) y en las condiciones institucionales (regulación). Estos dos elementos determinan la tendencia del crecimiento económico en el largo plazo. El trabajo productivo, por su parte, será el que establezca las posibilidades de acumulación de capital de largo plazo y transforme las acciones (incentivos) de los emprendedores mediante un incremento del ahorro. La importancia está centrada en la capacidad de los emprendedores de establecer procesos de generación de capital basados en el trabajo productivo y local (Alberdi, 1895a).

Las condiciones institucionales serán centrales para establecer incentivos de ahorro e inversión de largo plazo. Las características heredadas de la Colonia atentan contra este proceso, ya que limitan las oportunidades de inversión. La transformación de esta regulación requiere modificar las estrategias de apropiación de valor. Las continuas disputas territoriales y la consecuente inestabilidad en la gestión monetaria, impositiva y de endeudamiento condicionan las oportunidades de inversión y ahorro (Alberdi, 2008).

Respecto a las características cíclicas de los procesos de crecimiento, Alberdi centró su propuesta en la necesidad de estimular el crecimiento y la ve-
La vigencia del pensamiento de Juan Bautista Alberdi en el contexto latinoamericano: el rol del empresario

Miguel Francisco Gutiérrez 
locidad de las acciones como forma de contrarrestar las "crisis de pobreza". JBA adhiere a la teoría de ventajas absolutas como estrategia de crecimiento.

Lo que constituye la grande industria en Europa es el resultado de la evolución natural, porque pasa el poder productor de las sociedades civilizadas, a medida que su desarrollo toca sus más grandes consecuencias [...].

Tal desarrollo supone siglos de acumulación gradual de capitales y fuerzas y trabajo productor. (Alberdi, 1895b, p. 125)

Así, el trabajo productivo determina las posibilidades de generación de valor, el cual mediante el ahorro y la inversión produce capital. Este capital, a lo largo del tiempo y gracias a la especialización del uso de los factores productivos, genera condiciones de competitividad relativa al territorio.

La crisis de pobreza se relaciona con la falta de capital suficiente y la consolidación de procesos de bajo valor y competitividad. La escasez de trabajo productivo es la causa de la condición natural de pobreza de la Argentina del siglo XIX, en un contexto institucional inestable (revoluciones), con una política de crédito y emisión que empobrece y limita las posibilidades de planificar ahorro e inversión.

El trabajo debe contener características que representen su posibilidad de materializar procesos de ahorro e inversión, como parte de lo que Alberdi define como trabajo inteligente.

Pero el trabajo mismo no es causa de riqueza sino cuando reúne estas condiciones morales, a que debe su poder productivo:

1. Debe ser constante y persistente, es decir, un hábito, una educación.

2. Deber ser estudioso de su objeto y no meramente rutinario.

3. Debe ser libre y estar exento de toda traba colonial o restrictiva $y$ monopolista.

4. Debe estar armado de capitales, de vías de comunicación y transporte, de telégrafos, puertos, muelles, postas.

5. Seguro en sus funciones, establecimientos y resultados.

6. Ha de ser desempeñado con gusto, con amor del estado u oficio o profesión o carrera.

7. Ennoblecido y glorificado, si es posible, como el primer título de recomendación al aprecio y consideración del país.

8. Hacer de él la virtud democrática y republicana por excelencia y el arma predilecta de la libertad del hombre, como causa de riqueza, es decir, de poder, es decir, de autoridad y de independencia personal.

9. Debe tener el rango y honor que en las monarquías y aristocracias se da a la sociedad elegante y dispendiosa.

10. Habituado a la amistad inseparable e indispensable del agente que le da valor y honor, quiero hablar del hábito del ahorro, del juicio y del buen 
gusto, simple en los gastos, sin lo cual el trabajo es una vana y estéril tarea. (Alberdi, 1895b, p. 625)

Encontramos aquí una clara relación entre las características institucionales, la construcción moral de valores sociales y la relación con el mercado competitivo de las actividades del trabajo. Son las regulaciones de las relaciones sociales las que determinan el conjunto de condiciones que Alberdi expresa como necesarias para que el trabajo se convierta en valor (trabajo productivo) (Smith, 2011). Las expresiones verdaderas y últimas de este proceso son el ahorro y la inversión, mediante los cuales el trabajo adquiere la forma del emprendimiento. El emprendedor es el actor social de transformación en la teoría de Alberdi del crecimiento.

Para concluir el análisis del tipo de trabajo productivo que genera valor, es necesario definir el ahorro en el pensamiento de Alberdi para entender su vínculo con la inversión como causa y origen del valor. Son el ahorro y su consecuente inversión - y no el ahorro como atesoramiento- las expresiones del ahorro productivo.

Lejos de confundirse con los vicios de la avaricia y de la codicia, el ahorro es una virtud moral, la más bella cualidad de un hombre de buena educación y de buen gusto. Es una virtud que se compone de muchas otras: de previsión, de moderación, de dominio de sí mismo, de sobriedad, de orden. Es imposible llegar a la riqueza, sin la posesión de estas cualidades morales [...].

No hay más que ver cómo gasta un hombre su fortuna, para saber cuál es su educación, su moral, su inteligencia.

En una palabra, saber gastar es saber enriquecer sin empobrecer a nadie. (Alberdi, 1895b, p. 628)

En este esquema ideal, el emprendedor/empresario es el actor de transformación y de resultado de los procesos de regulación institucional. El emprendedor adquiere las virtudes del hombre liberal en la igualdad, la libertad y la simpatía. El proceso de competencia y de mercado promueve las iniciativas de ahorro e inversión que potencian la riqueza territorial y el desarrollo de capacidades. El emprendedor, mediante sus capacidades de previsión, de gestión y de perseverancia, promueve la transformación de los valores morales $\mathrm{y}$ transforma las relaciones sociales hacia una comunidad con mayor libertad y capacidades.

\section{El emprendedor como agente de transformación}

Es probable que JBA haya tomado la categoría de emprendedor que estableció Jean-Baptiste Say: la figura de un tomador de riesgos en la búsqueda de ganancias: "The entrepreneur shifts economic resources out of an area of lower and
La vigencia del pensamiento de Juan Bautista Alberdi en el contexto latinoamericano: el rol del empresario

Miguel Francisco Gutiérrez 
into an area of higher productivity and greater yield" [El empresario traslada los recursos económicos de una zona de menor productividad a otra de mayor productividad y rendimiento.] (Hindle, 2008, p. 77). Esta figura del emprendedor como un gestor del riesgo y la innovación, acuñada por Say a comienzos del siglo XIX en su Tratado de economía política (Say, 2001), es fundamental para la teoría económica y de la administración: la expresión de un individuo libre que representa las posibilidades de transformación social por medio de la innovación.

El desarrollo de la empresa, la innovación, la propensión a la toma de riesgos, la constancia en el trabajo y la búsqueda de riqueza son los valores necesarios para la transformación de la cultura argentina heredada. Estos se expresan en la figura de William Wheelwright, quien participó en el desarrollo de diversos proyectos y empresas en América del Sur durante el siglo XIX, y quien representaba para Alberdi el modelo de inmigrante necesario para la prosperidad regional.

La seguridad, la libertad y la igualdad son necesarias para el crecimiento del sector mercantil y de la burguesía nacional como clase. La transformación cultural depende en primera instancia de la reforma institucional que garanticen las libertades negativas como medios para el desarrollo de incentivos mercantiles. El crecimiento de la clase empresarial precisa los incentivos adecuados, y estos, las garantías institucionales de propiedad privada, paz y libertad.

Si bien Alberdi vivió en un período previo al desarrollo de la ciencia de la administración, comparte con ella preocupaciones teóricas en cuanto al objetivo final. Tanto JBA como los padres de la ciencia de la administración (Taylor, Fayol, Mayo) estudian mejoras en los métodos para el incremento de la riqueza.

Se puede ubicar el desarrollo de la ciencia de la administración en un momento del desarrollo del mercado en que el uso de los factores de producción necesita ser más intensivo y homogéneo para la estandarización de los procesos. Este objetivo de reducción de costos representa la profesionalización de la actividad empresarial: el emprendedor incorpora investigación sobre los procesos y sobre la organización como medio de estudio del negocio, y da paso al surgimiento de la administración como disciplina de estudio en sí misma.

Como resultado de los esfuerzos pragmáticos de la administración científica y el razonamiento administrativo, cambió el enfoque de "siempre-lo-hemos-hecho-de-esta-manera" al enfoque de "cuál-es-la-mejor-manera-de-hacerlo". Debemos enfatizar que estos administradores rompieron con la toma de decisiones tradicional, abogando por un enfoque administrativo basado en hechos $y$ en el razonamiento científico. (George et al., 2005, p. 118)

Para Frederick Winslow Taylor, "el objetivo principal de la administración ha de ser asegurar la máxima prosperidad para el patrón, junto con la máxima prosperidad para cada uno de los empleados" (Taylor, 1969, p. 19). El impacto 
económico de la ineficiencia humana a nivel macro es el objetivo principal del estudio de la administración; el remedio para la ineficiencia se origina en una cuestión administrativa, y no en habilidades extraordinarias que deberían tener los hombres (Taylor, 1969, pp. 16-17).

Henri Fayol realizará, para la misma época, un análisis de los problemas relacionados con la dirección, por lo que centrará su estudio en los niveles medios y gerenciales de la empresa. Fayol considera a la planificación como la principal capacidad, dada su complejidad e influencia para el éxito de la organización en el tiempo. "La previsión, la organización, la coordinación y el control forman parte, sin lugar a dudas, de la administración, de acuerdo con el concepto corriente de este término" (Fayol \& Taylor, 1994, p. 9).

JBA, por su parte, centró su interés en las condiciones institucionales necesarias para fomentar los incentivos al ahorro y a la inversión con fines comerciales. Producir es crear riqueza, y esta será parte de un proceso que requiere ciertos contextos "ambientales". Los valores liberales configuran las capacidades empresariales - la constancia (tolerancia a la frustración), la toma de riesgos y la búsqueda de beneficios - como una condición necesaria para la existencia de este proceso (Alberdi, 1887). Estas capacidades, relativas a la gestión administrativa, tienen en Alberdi una expresión cultural y moral, en que los comportamientos del pasado condicionan las preferencias adaptativas y las expectativas de los actores.

Alberdi comparte la idea de superar la tradición (antiguo régimen) como una necesidad, y demuestra su preocupación por la mejora en las condiciones y el desarrollo del mercado como espacio de realización social. Los incentivos liberales empresariales están en formación en Argentina durante este período, a partir de estructuras mixtas. Madurar como país es para Alberdi recorrer un camino hacia el liberalismo mediante estrategias institucionales que tomen en cuenta las características locales (territoriales).

En suma, el emprendedor representa la figura del agente de transformación de los valores morales y de las capacidades locales. Las posibilidades de consolidación de una burguesía argentina dependen para Alberdi de las regulaciones institucionales de las libertades negativas. El mercado es el espacio natural de regulación de las relaciones sociales para una sociedad liberal y, según Alberdi, es la expresión del progreso como institución.

Esta es la expresión que caracteriza el análisis de Alberdi sobre la necesidad de limitar las acciones del Estado como actor de consumos improductivos basados principalmente en gastos militares y de patronazgo. La función central del Estado es garantizar, como proveedor de bienes públicos, los principios liberales -el desarrollo de las iniciativas privadas de libertad social y crecimiento de mercado- que permiten que el mercado exista como institución.

La acción del emprendedor/empresario es resultado de este proceso, así como el medio para la consolidación del empresariado como actor político de representación. JBA reconoce a este actor de transformación en los productores agropecuarios y en los comerciantes, por ser los sectores dinámicos de
La vigencia del pensamiento de Juan Bautista Alberdi en el contexto latinoamericano: el rol del empresario

Miguel Francisco Gutiérrez 
crecimiento en la estructura productiva argentina. Garantizar el crecimiento económico basado en la especialización primaria es la estrategia que Alberdi adopta (ventajas comparativas) como medio de integración internacional. Las características particulares del territorio son las condiciones universales de producción de mercancías, de gestión de los procesos productivos y de administración empresarial (Ricardo, 2007).

\section{William Wheelwright: El modelo de empresario de Alberdi}

El monumento de William Wheelwright que se encuentra en Valparaíso es en parte un homenaje al pensamiento de Alberdi respecto de la necesidad de reemplazar las figuras heroicas de la independencia, vinculadas a valores relativos al honor, la gloria y la guerra, por un modelo nuevo de hombre, ligado a las condiciones necesarias para el logro genuino de la libertad (Alberdi, 1887, pp. 316-317). Estos valores modernos y liberales, vinculados al trabajo, la propiedad y la libertad, están emparentados, en el ideario alberdiano, a las posibilidades de alcanzar un estado de independencia efectivo (material).

Alberdi considera que es imprescindible que haya un cambio de actitud hacia el rol del empresario, quien debía ser visto como un héroe promotor del progreso. El nuevo paradigma debía ser el emprendedor que desarrolle industrias, abra nuevos mercados y comunique regiones que hasta ese momento permanecían improductivas con todo su potencial desaprovechado. (Newland \& Gómez, 2013, p. 32)

Los empresarios desarrollan capacidades que les permiten asumir tres tipos específicos de comportamiento: en primer lugar, aceptar los costos de cometer más errores y de mayor magnitud que los que cometerían si continuaran de la manera habitual; segundo, el comportamiento peculiar del hombre de negocios, la disposición a hacer las cosas de una forma diferente, a enfrentar las dificultades en las primeras etapas de su emprendimiento; y tercero, la superación al rechazo social, que se manifiesta en contra de quienes impulsan nuevos métodos de actuar (Schumpeter \& Backhaus, 2003, pp. 85-87). Estas características particulares del hacer colocan a los empresarios como promotores de un cambio posible en los valores relativos a la construcción de las relaciones sociales. Esta transformación se da mediante la realización de las actividades comerciales, que en la magnitud de los proyectos propuestos por Wheelwright transformarían el sistema productivo, las relaciones sociales y hasta el paisaje. 
Los derechos individuales estaban muy protegidos en la Constitución de 1853. Para Alberdi, el motor primario del crecimiento económico era el hombre. No solo era el hombre la base del trabajo, sino que la acumulación de capital, producto del trabajo previo, era imposible sin él. La tierra era improductiva si faltaba el hombre o el capital. Por lo tanto, pensaba Alberdi, la organización política debía extender la protección a las actividades económicas de todos los hombres en la Argentina -y aun ampliar sus privilegios-. (Brown, 1993, p. 70)

Esta transformación silenciosa tiene una base moral en la evolución de los valores: desde la gloria, el honor y la guerra, hacia la libertad, el trabajo y la paz. Expresa la importancia de la actividad productiva, científica, rutinaria, sistematizada, como consolidación de la independencia de un territorio que se vuelve capaz de bastarse a sí mismo por medio de su trabajo productivo e integración al mercado internacional. Es a través de la organización productiva y el uso intensivo de los factores de producción que la libertad será un hecho en la Argentina del siglo XIX.

La nueva política debe tender a glorificar los triunfos industriales, a ennoblecer el trabajo, a rodear de honor las empresas de colonización, de navegación y de industria, a reemplazar en las costumbres del pueblo, como estímulo moral, la vanagloria militar por el honor del trabajo, el entusiasmo guerrero por el entusiasmo industrial que distingue a los países libres de la raza inglesa, el patriotismo belicoso por el patriotismo de las empresas industriales que cambian la faz estéril de nuestros desiertos en lugares poblados $y$ animados. (Alberdi, 1887, p. 535)

Alberdi se encuentra entre los intelectuales que considera a los empresarios agentes estratégicos y fundamentales para la evolución social. Solo mediante su trabajo será posible avanzar en un proceso de acumulación genuino y contar con un aumento sistemático y continuo de la riqueza. En este sentido, el uso intensivo de los factores de producción es lo que hizo posible desde el siglo XVIII la revolución de las innovaciones y un crecimiento económico constante como nunca en la historia (Huntington et al., 2014).

Es importante señalar el interés intelectual de Alberdi por el estudio de los factores que promueven el crecimiento económico, sin avanzar en el análisis de la distribución del ingreso. Tal como señala Tulio Halperín Donghi (2007, p. 32), JBA se interesó en la creación de los beneficios materiales.

... los capitales extranjeros, atraídos y establecidos por el estímulo de una legislación de libertad, son el medio previsto por la Constitución para fomento de las empresas de ferrocarriles, de colonización, de líneas de vapores, bancos de circulación, seguros, etc. Pero los capitales no tienen el poder de llevar a cabo esas grandes empresas, sino por medio de la asociación. Los
La vigencia del pensamiento de Juan Bautista Alberdi en el contexto latinoamericano: el rol del empresario

Miguel Francisco Gutiérrez 
ferrocarriles, los canales, los bancos, las líneas de vapores, en ningún país del mundo son empresas que se acometan por un solo capitalista. Así, pues, la omnipotencia del capital, las maravillas de transformación y progreso que la América desierta espera de ese agente soberano de producción, residen y dependen de la asociación o compañía, que es la unión industrial de muchos para obtener un beneficio común. Este medio de acción del capital es igualmente aplicable a la producción agrícola, fabril y comercial. En todos los terrenos de la industria, la asociación es la fuerza que da al capital el poder de obrar resultados en grande escala. (Alberdi, 1853, p. 240)

Es necesario garantizar la paz, la estabilidad y la seguridad para brindar incentivos de inversión. Sin embargo, estas condiciones de base no aseguran por sí solas la acumulación de capital, para la cual se requieren incentivos económicos de mercado. Las condiciones particulares condicionan los incentivos para la generación de valor; el trabajo, el ahorro y la inversión son los procesos por los cuales se alcanzan la riqueza y la prosperidad efectivas del territorio. Garantizando un proceso de crecimiento sostenido en incentivos de mercado de largo plazo se superan las "crisis de pobreza" en la Argentina del siglo XIX. Este conjunto de condiciones universales (sobre las características de los procesos de generación de valor) y particulares (sistema productivo e institucional heredado) configura los límites y las oportunidades de crecimiento según JBA (Alberdi, 1853). La relación entre endeudamiento, guerra y crisis conforma un sistema correlacionado de causas que Alberdi señala como procesos constitutivos de crisis.

Como el poblador por excelencia es el capital, como no hay agente de inmigración de trabajadores igual al capital, que paga salarios atractivos y estimulantes al trabajo importando, es evidente que disminuir el capital del país, arruinarlo, exponerlo, es despoblar al país de su población más fecunda, que es la población obrera. Pues bien, acometer empresas de guerra o de mejoramiento material, superiores a los medios pecuniarios e inteligentes del país, es exponer el capital, disminuirlo, arruinarlo, perderlo y producir la crisis, que no es otra cosa que una gran destrucción de capital, es decir, un grande empobrecimiento general del país. (Alberdi, 1895b, p. 541; con énfasis en el original)

En síntesis, las garantías particulares sobre el sistema institucional hacen posible, según Alberdi, un proceso de crecimiento sostenido de acumulación de capital, donde las crisis pasan a ser de riqueza. La construcción de este proceso de crecimiento depende del emprendedor/empresario como agente de transformación económico y social (Gutiérrez, 2019). Las características institucionales heredadas del período colonial representan de este modo una limitación para el conjunto de países de América Latina. La organización extractiva de la producción sumada al escaso desarrollo del mecanismo de com- 
petencia de mercado limitó los incentivos de los emprendedores. Así pues, este sistema institucional promueve actividades rentísticas, reduciendo las dinámicas de crecimiento en la región. Superar el estado natural de pobreza en los territorios latinoamericanos depende entonces de refundar el orden institucional para establecer incentivos basados en la paz, el orden y los mecanismos de mercado como principal proceso de generación de valor.

\section{Referencias bibliográficas}

Acemoglu, D. \& Robinson, J. (2012). ¿Por qué fracasan los países? Los orígenes del poder, la prosperidad y la riqueza. ( $1^{\mathrm{a}} \mathrm{ed}$.). Ariel.

Alberdi, J. B. (1853). Sistema económico y rentístico de la Confederación Argentina según su Constitución de 1853. Vaccaro.

Alberdi, J. B. (1887). La vida y los trabajos industriales de William Wheelwright en América del Sud. En Obras completas de J. B. Alberdi, tomo VIII. La Tribuna Nacional.

Alberdi, J. B. (1895a). El crimen de la guerra. En Escritos póstumos, Tomo X (p. 322). Imprenta Europea, Moreno y Defensa.

Alberdi, J. B. (1895b). Estudios económicos. Tomo VIII. En Escritos póstumos. Imprenta Europea, Moreno y Defensa.

Alberdi, J. B. (2008). Notas para servir al estudio de las crisis. En Escritos Póstumos Vol. 1-XII, (pp. 705-735). Editorial Docencia.

Brown, J. C. (1993). Juan Bautista Alberdi y la doctrina del capitalismoliberal en la Argentina. Ciclos, no. 3(4), pp. 61-74.

Buchanan, J. M. \& Wagner, R. E. (2000). Democracy in Deficit: The Political Legacy of Lord Keynes. Liberty Fund.

Fayol, H. \& Taylor, F. W. (1994). Administración industrial y general coordinación, control, revisión, organización, mando [16 a ed.]. El Ateneo.

George, C. S., Alvarez Medina, M. de L. \& Maldonado Santa Cruz, G. (2005). Historia del pensamiento administrativo. Pearson Educación de México.

Graeber, D. (2018). Hacia una teoría antropológica del valor: La moneda falsa de nuestros sueños. Fondo de Cultura Económica.

Gutiérrez, M. F. (2019). El pensamiento de Juan Bautista Alberdi desde las ciencias económicas. En E. Pandís Pavlakis, D. L. Drosos, M. de Monserrat Llairó, V. Kritikou, E. Paraskevá (Eds.), ESTUDIOS Y HOMENAJES HISPANOAMERICANOS VI. Ediciones del Orto.

Halperín Donghi, T. (Ed.). (2007). Proyecto y construcción de una nación: 1846-1880, (1 ed.). Emecé Editores.

Hobsbawm, E. J. E. (2015). La era de la revolución (1789-1848), La era del capital (18481875), La era del imperio (1875-1914). (1ª ed.). Critica.

Huntington, S. P., Fukuyama, F. \& Oszlak, O. (2014). El orden político en las sociedades en cambio. Paidos.
La vigencia del pensamiento de Juan Bautista Alberdi en el contexto latinoamericano: el rol del empresario

Miguel Francisco Gutiérrez 
Artículos y ensayos Newland, C. \& Gómez, A. (2013). Alberdi, sobre héroes y empresarios. Revista Cultura Económica, no. 31(86).

North, D. C. (2014). Instituciones, cambio institucional y desempeño económico. Fondo de Cultura Económica.

Olivera, J. H. G. (1977). Economia Clasica Actual. Ediciones Macchi.

Ricardo, D. (2007). Principios de economía política y tributación. Editorial Claridad.

Say, J. B. (2001). Tratado de economía política. Fondo de Cultura Economica.

Schumpeter, J. A., Stiglitz, J. E., Díaz García, J., \& Limeres, A. (2015). Capitalismo, socialismo $y$ democracia. Página Indómita.

Schumpeter, J. \& Backhaus, U. (2003). The Theory of Economic Development. En J. Backhaus (Ed.), Joseph Alois Schumpeter (Vol. 1, pp. 61-116). Kluwer Academic Publishers. https:// doi.org/10.1007/0-306-48082-4_3

Smith, A. (2011). La riqueza de las naciones. Alianza Editorial SA.

Tarcus, H. (2016). El socialismo romántico en el Río de la Plata (1837-1852) (Primera edición). Fondo de Cultura Económica.

Taylor, F. W. (1969). Principios de la Administración Cientifica (11º). Herrero Hnos. S.A. 